\title{
Atividade respiratória e qualidade de beterraba inteira e minimamente processada
}

\author{
Alex Guimarães Sanches ${ }^{1}$, Maryelle Barros da Silva ${ }^{1}$, Elaine Gleice Silva Moreira ${ }^{1}$, Jaqueline \\ Macedo Costa ${ }^{1}$, Carlos Alberto Martins Cordeiro
}

${ }^{1}$ Universidade Federal do Pará, Campus de Altamira, Altamira-PA. E-mail: alexsanches.eng@gmail.com, maryellebarros@bol.com.br, elaine.moreira.230@gmail.com,jackmacedo@gmail.com

${ }^{2}$ Universidade Federal do Pará, Campus Bragança, Bragança-PA. E-mail: camcordeiro@ufpa.br

Recebido: 13/07/2016; Aceito: 21/08/2016

\section{RESUMO}

A beterraba (Beta vulgaris L.) é uma raiz tuberosa de grande importância agrícola e que vem ganhando espaço na linha de produtos minimamente processados. Todavia, o comportamento respiratório e a avaliação da qualidade pós-colheita dessa olerícola ainda é restrito principalmente quanto a melhor forma de processamento sendo este o principal objetivo desta pesquisa. As raízes foram armazenadas durante sete dias em refrigerador com temperatura de $5^{\circ} \mathrm{C}$ e avaliados diariamente quanto a taxa respiratória, a produção de etileno, o conteúdo de sólidos solúveis, acidez titulável, teor de ácido ascórbico e de betaleínas. A taxa respiratória e os teores de betalaínas foram afetados, independente do armazenamento, inteiro ou processado. De modo geral o armazenamento inteiro garantiu as melhores características em todas as variáveis avaliadas e na forma processada o corte em fatias manteve a preservação dos atributos relacionados à qualidade, ao metabolismo respiratório e aos pigmentos betalínicos, sendo, portanto, o recomendado para o processamento desta olerícola.

Palavras-chave: Beta vulgaris L., coloração, corte, metabolismo

\section{Respiratory activity and quality of beet and while minimally processed}

\begin{abstract}
The beet (Beta vulgaris L.) is a tuberous root of great importance to agriculture and has been gaining ground in the line of minimally processed products. However, respiratory behavior and evaluation of postharvest quality of this vegetable crop is still limited mainly as the best way of processing which is the main objective of this research. The roots were stored for seven days in a refrigerator at $5^{\circ} \mathrm{C}$ and evaluated daily for respiratory rate, ethylene production, content of soluble solids, titratable acidity and ascorbic acid content. The respiratory rate and betalains contents were affected regardless of the entire storage or processing. Overall the entire storage secured the best features in all variables and in processed form the slicing kept the preservation of attributes related to quality and the respiratory metabolism and betalínicos pigments, and is therefore recommended for processing vegetable crop.
\end{abstract}

Key-words: Beta vulgaris L., coloring, court, metabolism. 


\section{Introdução}

No Brasil, embora haja grande disponibilidade de produtos hortícolas acessíveis à substancial parcela da população, observam-se níveis inaceitáveis de perdas destes produtos devido a técnicas inadequadas adotadas desde a colheita até o armazenamento. Assim, o processamento mínimo de frutas e hortaliças pode contribuir com a redução de desperdícios, além de possibilitar maior praticidade e economia de tempo no preparo diário de alimentos, cada vez mais necessários ao agitado mundo moderno (ALVES et al., 2010).

Dentre as hortaliças minimamente processadas no Brasil, a beterraba (Beta vulgaris L.) vem aumentando a sua importância. A beterraba é uma raiz tuberosa de cor vermelho-arroxeada devido à presença de betalaínas, produtos naturais provenientes do metabolismo secundário e pertencentes ao grupo dos compostos secundários nitrogenados. Estes pigmentos, além de fornecer cor à beterraba, são importantes substâncias antioxidantes para a dieta humana, atuando na prevenção de alguns tipos de cânceres (VITTI et al., 2004).

De acordo com Chitarra e Chitarra (2007), frutas e hortaliças minimamente processadas mantêm seus tecidos vivos e não exibem a mesma resposta fisiológica que um tecido intacto tendo como consequência o desenvolvimento de sabores e odores desagradáveis e amaciamento dos tecidos. Esses mesmos autores complementam ainda que o aumento da perecibilidade de produtos minimamente processados está no aumento da taxa respiratória e na produção de etileno que aumentam a atividade enzimática devido à ruptura de muitas células.

Diante disso, o presente trabalho tem por objetivo avaliar o comportamento respiratório de beterrabas na forma inteira e minimamente processada por um período de sete dias em refrigeração.

\section{Material e Métodos}

Raízes tuberosas de beterraba, cultivar Itapuã foram colhidas nas primeiras horas da manhã em horta comercial localizada no município de Altamira-PA 65 dias após o plantio. Estas foram acondicionadas em caixas de madeira sendo então transportadas até o laboratório de Tecnologia Pós-colheita da faculdade de Engenharia Agronômica, UFPA- Campus Altamira-PA.

No laboratório as raízes foram lavadas em água corrente para a retirada das sujidades oriundas do cultivo e em seguida sanitizadas em solução contendo $5 \%$ de hipoclorito de sódio por cinco minutos. Após a sanitização estas foram enxaguadas em água corrente e então secas em temperatura ambiente.

O processamento mínimo foi realizado com auxílio de uma faca de aço inoxidável previamente esterilizada, sendo primeiramente eliminadas folhas e posteriormente as raízes que apresentavam defeitos para o processamento. As raízes foram submetidas a três tipos de cortes: fatias (com tamanho médio de $6 \mathrm{~cm}$ de comprimento e $3 \mathrm{~cm}$ de largura), rodelas (com diâmetro médio de $6 \mathrm{~cm}$ e largura de $3 \mathrm{~cm}$ ) e cubos (com peso médio de $6 \mathrm{~g}$ e tamanho médio de $3 \mathrm{~cm}$ ), além de raízes mantidas inteiras.

Com o intuito de eliminar o excesso da água as raízes processadas estas foram colocadas em sacos de nylon e submersos em água destilada a $5^{\circ} \mathrm{C}$ seguido de centrifugação por 30 segundos com rotação média de $1.500 \mathrm{rpm}$.

As raízes foram acondicionadas em bandejas de isopor de poliestireno revestida com filme plástico de PVC 14 micras e acondicionadas em refrigerador a $5^{\circ} \mathrm{C}$ $\left( \pm 1^{\circ} \mathrm{C}\right)$ e $\quad 85 \% \quad(5 \%$ de $\quad$ UR $)$, simulando a comercialização nos pontos de venda a varejo. O delineamento experimental adotado foi inteiramente casualizado com quatro tratamentos e dez repetições sendo a parcela experimental composta por bandejas de poliestireno contendo $120 \mathrm{~g}$ de raíz minimamente processada ou não.

As análises de taxa respiratória e produção de etileno foram determinadas cinco vezes a cada uma hora no dia zero e posteriormente foram avaliadas diariamente por um período de sete dias. Na tampa dos frascos foi colocado um septo de silicone através do qual foi retirada uma alíquota da atmosfera interna dos mesmos (1 mL) conforme recomendação da AOAC (2007).

A taxa respiratória e a produção de etileno foram determinadas por cromatografia gasosa em cromatógrafo Varian 3300. As amostras de cada repetição foram colocadas em minicâmaras hermeticamente fechadas sendo calculado o gás do espaço livre dos recipientes através de analisadores eletrônicos de $\mathrm{CO}_{2}$ e $\mathrm{C}_{2} \mathrm{H}_{4}$, marca Agri-Datalog. Com base na concentração de $\mathrm{CO}_{2}$, no volume do espaço livre, na massa de frutos e no tempo de fechamento, foi calculada a respiração e a produção de etileno sendo os valores expressos em mililitro de $\mathrm{CO}_{2} \mathrm{~kg}^{-1} \mathrm{~h}^{-1}$ e $\eta \mathrm{mol}$ $\mathrm{C}_{2} \mathrm{H}_{4} \mathrm{~kg}^{-1} \cdot \mathrm{h}^{-1}$, respectivamente, seguindo recomendação proposta por AOAC (2007).

O conteúdo de sólidos solúveis, acidez titulável e o teor de ácido ascórbico foram determinados apenas ao longo do tempo de armazenamento, seguindo a metodologia descrita por AOAC (2007), sendo os resultados expressos em ${ }^{\circ} \mathrm{Brix}, \mathrm{g} / 100 \mathrm{~g}$ ácido cítrico e $\mathrm{g} / 100 \mathrm{~g}$ ácido ascórbico polpa, respectivamente. Os teores de betalaínas (betacianina e betaxantina) foram determinados seguindo a metodologia descrita pelo Instituto Adolf Lutz (2008).

Os dados foram submetidos à análise de variância e a comparação das médias pelo teste de tukey a $5 \%$ de 
probabilidade após o teste de normalidade dos dados através do software estatístico BIOESTAT versão 4.3.

\section{Resultados e Discussão}

As raízes de beterraba minimamente processadas ou não apresentaram interação significativa quando avaliadas por um período de cinco horas e após sete dias de armazenamento refrigerado tanto para a taxa respiratória quanto para a produção etileno.

De acordo com a Tabela 1, nota-se que independente do tipo de corte adotado (fatias, rodelas e cubos), houve aumento significativo da taxa respiratória quando comparados às raízes mantidas inteiras, diferindo estatisticamente. Após 1 hora de armazenamento as raízes mantidas inteiras apresentaram valores médios de $12,13 \mathrm{~mL} \mathrm{CO} \mathrm{kg}^{-1} \mathrm{~h}^{-1}$ em relação aos 19,$35 ; 18,93$ e $19,75 \mathrm{~mL} \mathrm{CO} \mathrm{kg}^{-1} \mathrm{~h}^{-1}$ para fatias, rodelas e cubos respectivamente (Tabela 1 ).

O pico respiratório das raízes de beterraba processadas ou não foi observada após quatro horas de armazenamento quando as raízes mantidas inteiras apresentaram médias de 22,64 mL $\quad \mathrm{CO}_{2} \quad \mathrm{~kg}-1 \quad \mathrm{~h}^{-1}$ reduzindo para $16,54 \mathrm{~mL} \mathrm{CO} \mathrm{Kg}_{2} \mathrm{~h}^{-1}$ ao fim de cinco horas, diferindo significativamente dos demais tipos de cortes. Notou-se menor taxa respiratória quando cortados em fatias, verificando média de $42,91 \mathrm{~mL} \mathrm{CO}_{2}$ $\mathrm{kg}^{-1} \mathrm{~h}^{-1}$ ao fim de quatro horas, reduzindo para 34,57 $\mathrm{mL} \mathrm{CO} \mathrm{kg}^{-1} \mathrm{~h}^{-1}$ após cinco horas de armazenamento. Estes valores diferiram dos tratamentos com processamento na forma de rodelas e cubos cujas médias para os respectivos dias ultrapassaram $50 \mathrm{~mL}$ $\mathrm{CO}_{2} \mathrm{~kg}-1 \mathrm{~h}^{-1}$ e mantiveram-se entre 46,50 e 47,76 mL $\mathrm{CO}_{2} \mathrm{~kg}-1 \quad \mathrm{~h}^{-1}$ em análise após cinco horas, respectivamente (Tabela 1 ).

Com relação ao comportamento respiratório ao longo de sete dias de armazenamento, observa-se uma oscilação nos valores médios em todas as formas de processamento mínimo realizadas ou não principalmente do primeiro para o segundo dia de avaliação em todos os tratamentos. Ese aumento no início do armazenamento é decorrência da mudança de ambiente e do estresse causado seja pela colheita ou pelas etapas do processamento mínimo, corroborando assim com os resultados de Vitti et al., (2003) que evidenciaram aumento na taxa respiratória em beterrabas armazenadas a $5^{\circ} \mathrm{C}$ nos primeiros dias.

De modo geral as raízes mantidas inteiras apresentaram as menores variações ao longo de todo o experimento verificando pico respiratório no sexto dia de avaliação quando se observa média de $62,13 \mathrm{~mL} \mathrm{CO}_{2}$ $\mathrm{kg}-1 \mathrm{~h}^{-1}$, diferindo significativamente dos demais e verificando-se ainda pouca diferença nos valores médios do metabolismo respiratórios até o quinto dia de avaliação (Tabela 2).

Tabela 1. Valores médios sobre a taxa respiratória ( $\mathrm{mL} \mathrm{CO} 2 \mathrm{~kg}-1$ h-1) em raízes de beterrabas inteiras e minimamente processadas após cinco horas de armazenamento.

\begin{tabular}{cccccc}
\hline \multirow{2}{*}{ Tratamentos } & \multicolumn{5}{c}{ Horas após o armazenamento } \\
\cline { 2 - 5 } & 1 & 2 & 3 & 4 & 5 \\
Inteiro & $12,13 \mathrm{a}$ & $15,83 \mathrm{a}$ & $19,65 \mathrm{a}$ & $22,64 \mathrm{a}$ & $16,54 \mathrm{a}$ \\
Fatias & $19,35 \mathrm{~b}$ & $26,65 \mathrm{~b}$ & $35,18 \mathrm{~b}$ & $42,91 \mathrm{~b}$ & $34,57 \mathrm{~b}$ \\
Rodelas & $18,93 \mathrm{~b}$ & $31,18 \mathrm{bc}$ & $43,56 \mathrm{bc}$ & $50,22 \mathrm{bc}$ & $46,50 \mathrm{bc}$ \\
Cubos & $19,75 \mathrm{~b}$ & $30,93 \mathrm{bc}$ & $44,82 \mathrm{bc}$ & $51,38 \mathrm{bc}$ & $47,76 \mathrm{bc}$ \\
\hline CV $(\%)$ & 9,55 & 11,23 & 12,67 & 11,41 & 10,82 \\
\hline
\end{tabular}

Médias seguidas da mesma letra minúscula na coluna não diferem entre si, pelo teste de Tukey a 5\% de probabilidade.

Tabela 2. Valores médios sobre a taxa respiratória $\left(\mathrm{mL} \mathrm{CO}_{2} \mathrm{~kg}^{-1} \mathrm{~h}^{-1}\right)$ em raízes de beterrabas inteiras e minimamente processadas após sete dias de armazenamento.

\begin{tabular}{cccccccc}
\hline \multirow{2}{*}{ Tratamentos } & \multicolumn{7}{c}{ Dias de armazenamento } \\
\cline { 2 - 7 } & 1 & 2 & 3 & 4 & 5 & 6 & 7 \\
Inteiro & $12,13 \mathrm{a}$ & $28,43 \mathrm{a}$ & $39,03 \mathrm{a}$ & $25,18 \mathrm{a}$ & $49,27 \mathrm{a}$ & $62,13 \mathrm{a}$ & $51,23 \mathrm{a}$ \\
Fatias & $19,35 \mathrm{~b}$ & $46,54 \mathrm{~b}$ & $48,83 \mathrm{~b}$ & $98,53 \mathrm{~b}$ & $77,45 \mathrm{~b}$ & $83,21 \mathrm{~b}$ & $69,36 \mathrm{~b}$ \\
Rodelas & $18,93 \mathrm{~b}$ & $53,17 \mathrm{c}$ & $69,43 \mathrm{c}$ & $99,12 \mathrm{~b}$ & $75,65 \mathrm{~b}$ & $85,13 \mathrm{~b}$ & $73,18 \mathrm{~b}$ \\
Cubos & $19,75 \mathrm{~b}$ & $55,89 \mathrm{c}$ & $68,76 \mathrm{c}$ & $102,41 \mathrm{~b}$ & $79,67 \mathrm{~b}$ & $88,65 \mathrm{~b}$ & $76,47 \mathrm{~b}$ \\
\hline CV (\%) & 9,55 & 13,75 & 12,25 & 11,89 & 13,55 & 14,91 & 12,51 \\
\hline
\end{tabular}


Esses resultados corroboram com Verzeletti et al., (2010), que ao avaliarem a qualidade pós-colheita de cenoura minimamente processada notaram menor atividade respiratória quando houve o armazenamento no formato inteiro. Vitti et al. (2003) em experimento com beterrabas também evidenciaram oscilação nos valores de $\mathrm{CO}_{2}$ ao logo do armazenamento refrigerado.

Entre as formas processadas, o corte em fatias diferiu das demais até o terceiro dia de análise apresentando uma diferença de até $12,5 \mathrm{~mL} \mathrm{CO}_{2} \mathrm{~kg}^{-1} \mathrm{~h}^{-1}$ em relação ao corte em rodelas e cubos. No quarto dia todos os cortes apresentaram as maiores médias no decorrer do experimento, evidenciando dessa forma seu pico respiratório cujas médias chegaram a 98,53 99,32 e $102,41 \mathrm{~mL} \mathrm{CO}_{2} \mathrm{~kg}^{-1} \mathrm{~h}^{-1}$ para o corte fatias, rodelas e em cubos respectivamente (Tabela 2). O terço final de armazenamento não mostrou diferença entre os tipos de cortes, contudo o processamento no formato de cubos apresentou ainda as maiores variações, talvez pela maior superfície de exposição ao corte a que essas raízes foram submetidas.

Sasaki et al. (2006) e Verzeletti et al. (2010) também notaram maior respiração em abóboras e cenouras cortadas em cubos quando comparadas às formas de retalho e fatias respectivamente.

Em relação à produção de etileno, a detecção deste gás foi percebida apenas na primeira hora (Tabela 3) e no primeiro dia de armazenamento (Tabela 4) com resultado médio de 0,$11 ; 0,11$ e $0,12 \eta m_{0} \mathrm{C}_{2} \mathrm{H}_{4} \mathrm{~kg}^{-1} \cdot \mathrm{h}^{-1}$ para as raízes cortadas em fatias, rodelas e cubos respectivamente. Em raízes mantidas inteiras não foi registrada a ocorrência do etileno por sete dias em armazenamento refrigerado. Para as demais horas e tempos de armazenamento a produção deste gás foi inferior a $0,1 \eta$ mol $\mathrm{C}_{2} \mathrm{H}_{4} \quad \mathrm{~kg}^{-1} \cdot \mathrm{h}^{-1}$; limite mínimo detectado pelo cromatógrafo utilizado neste experimento. Para Reid (1992) a ocorrência abaixo de $0,1 \eta \mathrm{mol} \mathrm{C}_{2} \mathrm{H}_{4} \mathrm{~kg}^{-1} \cdot \mathrm{h}^{-1}$ caracteriza este regulador como inativo do ponto de vista fisiológico e da pós-colheita.

Os dados deste experimento concordam com vários estudos relatados na literatura tais como Vitti et al., (2004) que detectaram a produção de etileno em beterrabas minimamente processadas e por Kluge et al. (2010) que verificaram a ocorrência deste gás apenas no primeiro dia de armazenamento.

Tabela 3. Valores médios sobre a produção de etileno $\left(\eta m o l C_{2} \mathrm{H}_{4} \mathrm{~kg}^{-1} \cdot \mathrm{h}^{-1}\right)$ em raízes de beterrabas inteiras e minimamente processadas após cinco horas de armazenamento.

\begin{tabular}{|c|c|c|c|c|c|}
\hline \multirow{2}{*}{ Tratamentos } & \multicolumn{5}{|c|}{ Horas após o armazenamento } \\
\hline & 1 & 2 & 3 & 4 & 5 \\
\hline Inteiro & n.d & n.d & n.d & n.d & n.d \\
\hline Fatias & $0,11 \mathrm{a}$ & n.d & n.d & n.d & n.d \\
\hline Rodelas & $0,11 \mathrm{a}$ & n.d & n.d & n.d & n.d \\
\hline Cubos & $0,12 \mathrm{a}$ & n.d & n.d & n.d & n.d \\
\hline $\mathrm{CV}(\%)$ & 0,22 & 0,0 & 0,0 & 0,0 & 0,0 \\
\hline
\end{tabular}

Médias seguidas da mesma letra minúscula na coluna não diferem entre si, pelo teste de Tukey a $5 \%$ de probabilidade. nd= não detectado.

Tabela 4. Valores médios sobre a produção de etileno ( $\eta$ mol $\mathrm{C} 2 \mathrm{H} 4 \mathrm{~kg}-1 . \mathrm{h}-1$ ) em raízes de beterrabas inteiras e minimamente processadas após sete dias de armazenamento.

\begin{tabular}{|c|c|c|c|c|c|c|c|}
\hline \multirow{2}{*}{ Tratamentos } & \multicolumn{7}{|c|}{ Dias de armazenamento } \\
\hline & 1 & 2 & 3 & 4 & 5 & 6 & 7 \\
\hline Inteiro & n.d & n.d & n.d & n.d & n.d & n.d & n.d \\
\hline Fatias & $0,11 \mathrm{a}$ & n.d & n.d & n.d & n.d & n.d & n.d \\
\hline Rodelas & $0,11 \mathrm{a}$ & n.d & n.d & n.d & n.d & n.d & n.d \\
\hline Cubos & $0,12 \mathrm{a}$ & n.d & n.d & n.d & n.d & n.d & n.d \\
\hline $\mathrm{CV}(\%)$ & 0,21 & 0 & 0 & 0 & 0 & 0 & 0 \\
\hline
\end{tabular}

Médias seguidas da mesma letra minúscula na coluna não diferem entre si, pelo teste de Tukey a $5 \%$ de probabilidade. nd= não detectado. 
No que tange ao conteúdo de sólidos solúveis, este foi significativamente maior nas raízes mantidas inteiras ao longo do armazenamento refrigerado; para este tratamento verifica-se médias oscilando do início ao fim do experimento entre 12,2 e $10,8^{\circ}$ Brix enquanto que para as amostras processadas em diferentes formas a média oscilou entre 8,6 e $6,4^{\circ}$ Brix, sendo o corte em rodelas o que apresentou os menores percentuais, contudo sem diferir estatisticamente dos demais (Tabela 5). Esses menores teores verificados nas amostras processadas já eram esperados uma vez que a intensidade de ferimentos provocados pelo corte tem como consequência o maior extravasamento do suco celular, particularmente os teores de carboidratos solúveis, os maiores componentes dos sólidos solúveis.

Apesar da estabilidade inicial verificada nas raízes mantidas inteiras, estas apresentaram reduções no conteúdo de SS a partir do sexto dia de armazenamento. No corte em rodelas e em cubos nota-se uma redução a partir do quarto dia de avaliação passando de 6,8 e 6,4 ${ }^{\circ}$ Brix para 4,5 e $4,2^{\circ}$ Brix respectivamente (Tabela 5). $\mathrm{O}$ corte em fatias manteve certa estabilidade no decorrer do armazenamento com valores na faixa de 8,6 e 5,4 ${ }^{\circ}$ Brix, essa menor variação evidenciada pelo corte em fatias nos permite concluir que o tipo de corte influi diretamente no teor de SS, não havendo diferença do tempo de conservação na sua manutenção. Kluge et al. (2006) avaliando diferentes tipos de cortes na conservação de beterrabas também observou manutenção no conteúdo de SS com o corte em fatias em ralação ao corte em cubo e retalhos

Os valores médios de acidez titulável, observado neste experimento (Tabela 6), apresentaram aumento com o tempo de armazenamento em todos os tratamentos, sendo maior quando os frutos foram processados independente do corte realizado. Em média os valores passaram de 0,05 para 0,23 g/100 g ácido cítrico. Esse aumento nos valores de acidez pode ter sido provocado pelo processo de fermentação das amostras que, mantidas em potes de vidro, não realizaram troca gasosa com o ambiente externo da forma como ocorre com as bandejas de poliestireno e os filmes plásticos de PVC.

Moretti (2007), explica que o nível de acidez dos frutos é determinado pela quantificação dos ácidos orgânicos presentes nas frutas e hortaliças seja na forma natural ou acumulada em consequência do processo de fermentação ou por adição destes durante o processamento, conforme verificado neste trabalho. $\mathrm{O}$ teor de ácido ascórbico no início do experimento variou em média 14,06 g/100 g ácido ascórbico para os frutos inteiros e em média 13,79 e 13,86 g/100 g ácido ascórbico para as raízes processadas, corroborando com o percentual médio encontrado por Marques et al. (2010), que avaliando a qualidade de beterrabas verificaram percentual médios de 11,41 a $14,11 \mathrm{~g} / 100 \mathrm{~g}$ ácido ascórbico conforme as médias obtidas neste trabalho.

Tabela 5. Valores médios sobre o conteúdo de sólidos solúveis ( ${ }^{\circ}$ Brix) em raízes de beterrabas inteiras e minimamente processadas após sete dias de armazenamento

\begin{tabular}{ccccccccc}
\hline \multirow{2}{*}{ Tratamentos } & \multicolumn{7}{c}{ Dias de armazenamento } \\
\cline { 2 - 8 } & 1 & 2 & 3 & 4 & 5 & 6 & 7 \\
Inteiro & $12,2 \mathrm{a}$ & $11,1 \mathrm{a}$ & $11,6 \mathrm{a}$ & $11,4 \mathrm{a}$ & $11,6 \mathrm{a}$ & $11,1 \mathrm{a}$ & $10,8 \mathrm{a}$ \\
Fatias & $8,6 \mathrm{~b}$ & $8,4 \mathrm{~b}$ & $7,9 \mathrm{~b}$ & $7,5 \mathrm{~b}$ & $7,0 \mathrm{bc}$ & $6,3 \mathrm{~b}$ & $5,4 \mathrm{~b}$ \\
Rodelas & $8,4 \mathrm{~b}$ & $8,0 \mathrm{~b}$ & $7,5 \mathrm{~b}$ & $6,8 \mathrm{~b}$ & $6,0 \mathrm{c}$ & $5,4 \mathrm{c}$ & $4,5 \mathrm{c}$ \\
Cubos & $8,4 \mathrm{~b}$ & $7,9 \mathrm{~b}$ & $7,4 \mathrm{~b}$ & $6,4 \mathrm{~b}$ & $5,9 \mathrm{c}$ & $5,0 \mathrm{c}$ & $4,3 \mathrm{c}$ \\
\hline CV $(\%)$ & 1,36 & 2,75 & 2,45 & 3,31 & 2,64 & 1,89 & 2,76 \\
\hline
\end{tabular}

Médias seguidas da mesma letra minúscula na coluna não diferem entre si, pelo teste de Tukey a 5\% de probabilidade.

Tabela 6. Valores médios sobre o teor de acidez titulável (g/100g ácido cítrico) em raízes de beterrabas inteiras e minimamente processadas após sete dias de armazenamento.

\begin{tabular}{ccccccccc}
\hline \multirow{2}{*}{ Tratamentos } & \multicolumn{7}{c}{ Dias de armazenamento } \\
\cline { 2 - 8 } & 1 & 2 & 3 & 4 & 5 & 6 & 7 \\
Inteiro & $0,05 \mathrm{a}$ & $0,021 \mathrm{a}$ & $0,035 \mathrm{a}$ & $0,058 \mathrm{a}$ & $0,074 \mathrm{a}$ & $0,089 \mathrm{a}$ & $0,099 \mathrm{a}$ \\
Fatias & $0,012 \mathrm{~b}$ & $0,33 \mathrm{~b}$ & $0,52 \mathrm{~b}$ & $0,67 \mathrm{~b}$ & $0,86 \mathrm{~b}$ & $0,9 \mathrm{~b}$ & $0,21 \mathrm{~b}$ \\
Rodelas & $0,013 \mathrm{~b}$ & $0,46 \mathrm{~b}$ & $0,51 \mathrm{~b}$ & $0,64 \mathrm{~b}$ & $0,99 \mathrm{~b}$ & $0,13 \mathrm{~b}$ & $0,23 \mathrm{~b}$ \\
Cubos & $0,012 \mathrm{~b}$ & $0,41 \mathrm{~b}$ & $0,55 \mathrm{~b}$ & $0,73 \mathrm{~b}$ & $0,3 \mathrm{~b}$ & $0,15 \mathrm{~b}$ & $0,23 \mathrm{~b}$ \\
\hline CV $(\%)$ & 0,89 & 0,77 & 1,12 & 1,85 & 2,27 & 0,91 & 0,41 \\
\hline
\end{tabular}

Médias seguidas da mesma letra minúscula na coluna não diferem entre si, pelo teste de Tukey a 5\% de probabilidade. 
As raízes mantidas inteiras apresentaram pouca redução no teor de ácido ascórbico com significância maior no sexto dia de avaliação quando a diferença média foi de 2,21 g/100 g ácido ascórbico na polpa, em relação aos demais dias de armazenamento (Tabela 7).

$\mathrm{O}$ corte em rodelas seguido do corte em fatias apresentou as maiores perdas durante todo o período de avaliação, talvez pelo aumento da área de contato da beterraba com fatores do ambiente tais como (calor, luz, oxigênio), favorecendo a descompartimentação celular. $\mathrm{O}$ corte em cubos apresentou as menores perdas ao longo de todo o tempo de armazenamento, contudo, sem diferir estatisticamente das demais formas processadas (Tabela 7). Para Sasaki et al., (2006) a redução no teor de vitamina $\mathrm{C}$ é reduzido de acordo com o tipo de corte utilizado.

As betalaínas são produtos naturais hidrossolúveis provenientes do metabolismo secundário e pertencentes ao grupo dos compostos secundários nitrogenados sendo divididos em duas classes: as betacianinas (cor avermelhada) e as betaxantinas (cor amarelada); estes pigmentos são responsáveis pela coloração da beterraba além de serem importantes substâncias antioxidantes.

De acordo com os dados apresentados na Tabela 8, os teores de betalaínas foram significativamente afetados pelo processamento mínimo quando comparados às raízes mantidas inteiras já no primeiro dia de avaliação.

Por serem pigmentos solúveis em água, os processos de sanitização e enxague realizados nas etapas do processamento mínimo contribuiu significativamente para a redução destes teores. Mesmo mantidas em refrigeração o índice de betalaínas reduziu em torno de $10 \%$ nas raízes mantidas inteiras, revelando assim sua degradação independente da forma de processamento e ou acondicionamento (Tabela 8).

Tabela 7. Valores médios sobre o teor de ácido ascórbico (g/100g ácido ascórbico polpa) em raízes de beterrabas inteiras e minimamente processadas após sete dias de armazenamento.

\begin{tabular}{ccccccccc}
\hline \multirow{2}{*}{ Tratamentos } & \multicolumn{7}{c}{ Dias de armazenamento } \\
\cline { 2 - 8 } & 1 & 2 & 3 & 4 & 5 & 6 & 7 \\
Inteiro & $14,06 \mathrm{a}$ & $14,01 \mathrm{a}$ & $13,93 \mathrm{a}$ & $13,52 \mathrm{a}$ & $13,13 \mathrm{a}$ & $11,87 \mathrm{a}$ & $11,44 \mathrm{a}$ \\
Fatias & $13,86 \mathrm{a}$ & $13,21 \mathrm{~b}$ & $12,63 \mathrm{~b}$ & $10,84 \mathrm{~b}$ & $9,43 \mathrm{~b}$ & $7,31 \mathrm{~b}$ & $5,41 \mathrm{~b}$ \\
Rodelas & $13,83 \mathrm{a}$ & $13,25 \mathrm{~b}$ & $12,54 \mathrm{~b}$ & $10,92 \mathrm{~b}$ & $9,55 \mathrm{~b}$ & $7,29 \mathrm{~b}$ & $5,32 \mathrm{~b}$ \\
Cubos & $13,79 \mathrm{a}$ & $13,44 \mathrm{~b}$ & $12,71 \mathrm{~b}$ & $11,06 \mathrm{~b}$ & $9,66 \mathrm{~b}$ & $7,55 \mathrm{~b}$ & $5,47 \mathrm{~b}$ \\
\hline CV (\%) & 8,56 & 6,79 & 6,72 & 7,34 & 7,98 & 8,13 & 8,34 \\
\hline
\end{tabular}

Médias seguidas da mesma letra minúscula na coluna não diferem entre si, pelo teste de Tukey a 5\% de probabilidade.

Tabela 8. Valores médios sobre o teor de betalaínas $(\mathrm{mg} / 100 \mathrm{~g}$ de betacianina e betaxantina) em raízes de beterrabas inteiras e minimamente processadas após sete dias de armazenamento.

\begin{tabular}{|c|c|c|c|c|c|c|c|}
\hline \multirow{3}{*}{ Tratamentos } & \multicolumn{7}{|c|}{ Dias de armazenamento } \\
\hline & \multicolumn{7}{|c|}{ Betacianinas (mg/100g de polpa) } \\
\hline & 1 & 2 & 3 & 4 & 5 & 6 & 7 \\
\hline Inteiro & $98,54 \mathrm{a}$ & 96,57 a & 94,16 a & $91,83 \mathrm{a}$ & 89,79 a & 88,35 a & $86,13 \mathrm{a}$ \\
\hline Fatias & $83,87 \mathrm{~b}$ & $77,12 \mathrm{~b}$ & $70,49 \mathrm{~b}$ & $66,39 \mathrm{~b}$ & $61,08 \mathrm{~b}$ & $57,12 \mathrm{~b}$ & $51,67 \mathrm{~b}$ \\
\hline Rodelas & $77,21 \mathrm{c}$ & $70,33 \mathrm{c}$ & $66,34 \mathrm{c}$ & $59,25 \mathrm{c}$ & $50,32 \mathrm{c}$ & $44,98 \mathrm{c}$ & $40,12 \mathrm{c}$ \\
\hline Cubos & $79,03 \mathrm{c}$ & $72,76 \mathrm{c}$ & $69,45 \mathrm{c}$ & 57,34 & $52,18 \mathrm{c}$ & $45,13 \mathrm{c}$ & $41,57 \mathrm{c}$ \\
\hline \multirow[t]{2}{*}{$\mathrm{CV}(\%)$} & 12,87 & 11,08 & 12,67 & 13,98 & 14,26 & 10,13 & 14,51 \\
\hline & \multicolumn{7}{|c|}{ Betaxantina (mg/100g de polpa) } \\
\hline Inteiro & 94,33 & 92,78 a & $90,45 \mathrm{c}$ & 87,43 a & 83,21 a & 78,13 a & $74,91 \mathrm{a}$ \\
\hline Fatias & $81,18 \mathrm{~b}$ & $74,67 \mathrm{~b}$ & $68,02 \mathrm{~b}$ & $60,78 \mathrm{~b}$ & $54,34 \mathrm{~b}$ & $47,05 \mathrm{~b}$ & $41,36 \mathrm{~b}$ \\
\hline Rodelas & $67,43 \mathrm{c}$ & $60,45 \mathrm{c}$ & $55,38 \mathrm{c}$ & $47,78 \mathrm{c}$ & $36,35 \mathrm{c}$ & $31,56 \mathrm{c}$ & $22,41 \mathrm{c}$ \\
\hline Cubos & $61,34 \mathrm{c}$ & $60,56 \mathrm{c}$ & $55,09 \mathrm{c}$ & $46,18 \mathrm{c}$ & $38,03 \mathrm{c}$ & 29,22 c & $23,96 \mathrm{c}$ \\
\hline $\mathrm{CV}(\%)$ & 13,93 & 12,45 & 11,87 & 11,4 & 12,04 & 13,21 & 14,67 \\
\hline
\end{tabular}

Médias seguidas da mesma letra minúscula na coluna não diferem entre si, pelo teste de Tukey a 5\% de probabilidade. 


\section{Conclusões}

As raízes de beterraba inteiras apresentam aumento na taxa respiratória e redução nos pigmentos de betalaínas mesmo em ambiente refrigerado, favorecendo a redução da vida de prateleira.

$\mathrm{Na}$ forma processada o corte em fatias é o mais recomendado para o processamento mínimo de beterrabas, pois garantiu menor taxa respiratória, preservou os pigmentos das betalaínas e manteve em equilíbrio o teor de sólidos solúveis e a acidez titulável sem comprometer o teor de ácido ascórbico quando comparado aos demais cortes.

\section{Referências Bibliográficas}

ALVES, J. A.; VILAS BOAS, E. V. de. B.; VILAS BOAS, B. M.; SOUZA, E. C. de. Qualidade de produto minimamente processado à base de abóbora, cenoura, chuchu e mandioquinha-salsa. Ciência e Tecnologia de Alimentos. Campinas-SP, v. 30, n. 3, p. 625-634, 2010.

AOAC. ASSOCIATION OF OFFICIAL ANALYTICAL CHEMISTS. Official methods of the Association of the Agricultural Chemists. $17^{\text {th }}$ ed. Washington, 2007. $1410 \mathrm{p}$.

ChItARRA, M. I.; CHITARRA; A. B. Pós-colheita de frutas e hortaliças: fisiologia e manuseio. $2^{\mathrm{a}}$ ed. Lavras-MG: Universidade Federal de Lavras, 2007. 785 p.

IAL. INSTITUTO ADOLFO LUTZ. Normas Analíticas do Instituto Adolfo Lutz: Métodos químicos e físicos para análise de alimentos. $4^{\mathrm{a}}$ ed. São Paulo-SP: Instituto Adolfo Lutz, 2008. 1020 p.

KLUGE, R. A.; COSTA, K. A.; VITTI, M. C. D.; ONGARELLI, M. G.; JACOMINO, A. P.; MORETTI, C. L. Armazenamento refrigerado de beterraba minimamente processada em diferentes tipos de cortes. Ciência Rural, Santa Maria-RS, v. 36, n. 1, p. 263-270, 2006.
KLUGE, R.A; PICOLI, A.A.; AGUILA, J.S. Respiração e produção de etileno em beterrabas inteiras e minimamente processadas submetidas a tratamentos com etileno e biorreguladores. Horticultura Brasileira, Brasília-DF, v. 28, n. 1, p. $54-57,2010$.

MARQUES, L. F.; MEDEIROS, C. D.; COUTINHO, O. L.; MEDEIROS, C. B.; VALE, L. S. Produção e qualidade da beterraba em função da adubação com esterco bovino. Revista Brasileira de Agroecologia, Porto Alegre-RS, v. 5, n. 1, p. 24-31, 2010

MORETTI, C. L. Manual de processamento mínimo de frutas e hortaliças, Brasília-DF: Embrapa Hortaliças, SEBRAE, p. 531, 2007.

REID, M. S. Ethylene in postharvest technology. In: KADER, A. A. (Ed.). Postharvest technology of horticultural crops. Oakland: University of California, cap. 13, 1992. p. 97-108,

SASAKI, F. F.; DEL AGUILA, J. S.; GALLO, C. R.; ORTEGA, E. M. M.; JACOMINO, A. P.; KLUGE, R. A Alterações fisiológicas, qualitativas e microbiológicas durante o armazenamento de abóbora minimamente processada em diferentes tipos de corte. Horticultura Brasileira, BrasíliaDF, v. 24, n. 2, p. 170-174, 2006.

VERZELETTI, A.; FONTANA, R. C.; SANDRI, I. G. Avaliação da vida de prateleira de cenouras minimamente processadas. Alimentos e Nutrição, Araraquara-SP, v.21, n.1, p. 87-92, 2010.

VITTI, M. C. D.; KLUGE, R. A.; YAMAMOTTO, L. K; JACOMINO, A. P. Comportamento da beterraba minimamente processada em diferentes espessuras de corte. Horticultura Brasileira, Brasília-DF, v. 21, n. 4, p.623-626, 2003.

VITTI, M. C. D.; KLUGE, R. A.; GALLO, C. R.; SCHIAVINATO, M. A.; MORETTI, C. L.; JACOMINO, A. P. Aspectos fisiológicos e microbiológicos de beterrabas minimamente processadas. Pesquisa Agropecuária Brasileira, Brasília-DF, v. 39, n. 3, p. 1027-1032, 2004 